\title{
Sliding wear behavior of FeCrC reinforced and Ni-based composites produced by mechanical alloying technique
}

\author{
S. O. Yilmaz ${ }^{1}$, F. Demir ${ }^{2}$, T. Teker ${ }^{3 *}$ \\ ${ }^{1}$ Namık Kemal University, Faculty of Engineering, Department of Mechanical Engineering, \\ 59100 Çorlu, Tekirdă̆, Turkey \\ ${ }^{2}$ Batman University, Faculty of Engineering, Department of Metallurgical and Materials Engineering, \\ 76100 Adryaman, Turkey \\ ${ }^{3}$ Adryaman University, Faculty of Engineering, Department of Metallurgical and Materials Engineering, \\ 02040 Adryaman, Turkey
}

Received 29 June 2015, received in revised form 20 February 2017, accepted 21 February 2017

\begin{abstract}
The study presents the behavior of $\mathrm{FeCrC}$ particulates reinforced and Ni-based composites produced by a mechanical alloying process in the presence of friction and wear. $\mathrm{Ni}, \mathrm{Al}$ and $\mathrm{M}_{7} \mathrm{C}_{3}$ powders having $100 \mu \mathrm{m}$ size were mixed, mechanically alloyed and the compacts were sintered in an atmosphere controlled furnace. The mechanically alloyed (MAed) samples were investigated by SEM, EDS and DTA. For the wear tests, the samples were tested in dry conditions. The worn surfaces were examined using OM to study the wear behavior. The friction coefficient was recorded continuously during the wear test and wear rate. The highest wear rate was obtained at $800^{\circ} \mathrm{C}$, and the lowest was obtained at $900^{\circ} \mathrm{C}$. With the increase of reinforcement amount, wear rate decreased.
\end{abstract}

Ke y words: metal matrix composites, mechanical alloying, abrasion, thermal analysis

\section{Introduction}

$\mathrm{NiAl}$ is an ideal superalloy material especially in extreme temperature applications as well as corrosive surroundings due to its above average resistance to corrosion. Other beneficial properties attached to $\mathrm{NiAl}$ include high thermal conductivity, low density as well as a high melting point [1-3]. There exists an innovative method for developing nanostructured coatings on different metal surfaces named mechanical alloying (MA). The method is guided by principle indicating that on top of the vibration compartment should be a fixed substrate while the powder and ball should be weighted into it. The coating forms as a result of the powder particles being cold welded to the surface as well as the ball causing an impact on the substrate's surface $[4,5]$. The critical feature that defines the process is when the ball comes across the condensed grain structure to the nanometer scale. Owing to the ball encounters there is the creation of coatings that are illustrated in the intermixture of the materials both at the coating layers as well as the probable formation of a composite layer surface $[6,7]$.

MA is regarded as one of the simplest and the most economical techniques to form a solid solution and to produce the fine-grained alloy. MA is a solidstate powder process covering multiple mechanisms of plastic deformation, cold-welding, fracturing and mechanically activated interdiffusion among the particles. In addition, MA has been successfully employed to achieve a nearly homogeneous solid solution when compared to the same alloy obtained by conventional ingot metallurgy [8].

Mohammadnezhad et al. studied the formation of nanostructured $\mathrm{NiAl}$ coating on carbon steel by using mechanical alloying. The coating in the $\mathrm{NiAl}$ nanocrystalline grains ranged between 28 to $130 \mu \mathrm{m}$. Consequently, forming of the coatings was noted to range between 60 and $600 \mathrm{~min}$. At $480 \mathrm{~min}$, the surface layers had an average thickness of $470 \mu \mathrm{m}$ and an average hardness of $930 \mathrm{HV}$ [9].

The aim of the present work was to investigate

\footnotetext{
*Corresponding author: tel.: +90 416 2233800; fax: +90 416 2233809; e-mail address: tteker@adivaman.edu.tr
} 
Table 1. The chemical composition of Ni powder used in experiments (wt.\%)

\begin{tabular}{cc}
\hline $\mathrm{Ni}$ & Other \\
\hline 99.98 & 0.02 \\
\hline
\end{tabular}

Table 2. The chemical composition of Al powders used in experiments (wt.\%)

\begin{tabular}{ccccccc}
\hline $\mathrm{Al}$ & $\mathrm{Fe}$ & $\mathrm{Si}$ & $\mathrm{Cu}$ & $\mathrm{Zn}$ & $\mathrm{Ti}$ & Other \\
\hline 99.5 & 0.4 & 0.25 & 0.05 & 0.05 & 0.04 & 0.01 \\
\hline
\end{tabular}

Table 3. The chemical composition of $\mathrm{FeCrC}$ powders used in experiments (wt.\%)

\begin{tabular}{cccccc}
\hline $\mathrm{C}$ & $\mathrm{S}$ & $\mathrm{Cr}$ & $\mathrm{Fe}$ & $\mathrm{Si}$ & $\mathrm{P}$ \\
\hline 7.6 & 0.003 & 70 & 20.7 & 1.6 & 0.03 \\
\hline
\end{tabular}

wear resistance of $\mathrm{FeCrC}$ reinforced and Ni-based composites by mechanical alloying because industrial applications of intermetallic NiAl compound can be used.

\section{Experimental procedures}

In the produced samples, $\mathrm{Ni}$ and $\mathrm{Al}$ powders were used as the matrix, and the high-carbon Fe-
CrC powder was used as the reinforcing member. The size of the used $\mathrm{Ni}$ and $\mathrm{Al}$ powders is $100 \mu \mathrm{m}$, and the size of the FeCrC powder is $37-63 \mu \mathrm{m}$. Chemical compositions of $\mathrm{Ni}, \mathrm{Al}$ and $\mathrm{FeCrC}$ powders are given in Tables 1-3. $\mathrm{Ni}, \mathrm{Al}$ and $\mathrm{FeCrC}$ powders were subjected to mechanical alloying procedure together. The experimental procedure parameters are given in Table 4. The metallographic analysis was done by a conventional method. The sintered samples were cut and mechanically polished and etched with $2 \%$ nital. Etched samples were photographed in the optical microscope (OM), Scanning Electron Microscopy (SEM), and Energy Dispersive Spectrometry (EDS) analyses for the elementary content of phases on the interface of samples were taken. Then, phase transformation analysis was made using a Setaram type Differential Thermal Analysis (DTA) device, under an Ar atmosphere at a heating rate of $0.33 \mathrm{~K} \mathrm{~s}^{-1}$.

The wear resistance of the mechanically alloyed samples was obtained by carrying out wear tests in the pin-on-disc apparatus according to the standard ASTM-G 99, keeping sliding distance, applied normal load and sliding velocity constant. Before the wear test, the surface of samples was ground on $\mathrm{SiC}$ abrasive paper to remove any oxidized layer. Wear tests were conducted under a normal load of $40 \mathrm{~N}$, and at a constant rotation speed of $66.7 \mathrm{~m} \mathrm{~s}^{-1}$ in dry condition. It was interrupted each $300 \mathrm{~m}$ to allow intermediate measurements of a disc lost mass. The wear rate of the samples was measured by using a digital microbalance with an accuracy of $0.1 \mathrm{mg}$. The friction coefficients were recorded continuously during the wear test.

Table 4. The parameters used in experiments and the produced samples

\begin{tabular}{|c|c|c|c|c|}
\hline $\begin{array}{l}\text { Sample } \\
\text { No }\end{array}$ & $\begin{array}{l}\text { Sintering temperature } \\
\left({ }^{\circ} \mathrm{C}\right)\end{array}$ & $\begin{array}{l}\text { Sintering time } \\
(\mathrm{h})\end{array}$ & $\begin{array}{l}\text { Grinding time } \\
(\mathrm{h})\end{array}$ & $\begin{array}{c}\text { Reinforcement ratio } \\
\text { (wt.\%) }\end{array}$ \\
\hline S1.1 & 800 & 1 & 1 & 10 \\
\hline $\mathrm{S} 1.2$ & 800 & 2 & 1 & 10 \\
\hline S2.1 & 900 & 1 & 1 & 0 \\
\hline $\mathrm{S} 2.2$ & 900 & 1 & 1 & 5 \\
\hline $\mathrm{S} 2.3$ & 900 & 1 & 1 & 10 \\
\hline S2.4 & 900 & 1 & 1 & 20 \\
\hline S2.5 & 900 & 1 & 1 & 30 \\
\hline S3.1 & 900 & 2 & 1 & 5 \\
\hline S 3.2 & 900 & 2 & 1 & 10 \\
\hline S3.3 & 900 & 2 & 1 & 20 \\
\hline S4.1 & 1000 & 2 & 1 & 0 \\
\hline $\mathrm{S} 4.2$ & 1000 & 2 & 1 & 5 \\
\hline S4.3 & 1000 & 2 & 1 & 10 \\
\hline S4.4 & 1000 & 2 & 1 & 20 \\
\hline S5.1 & 1100 & 2 & 1 & 5 \\
\hline S5.2 & 1100 & 2 & 1 & 10 \\
\hline S5.3 & 1100 & 2 & 1 & 20 \\
\hline
\end{tabular}



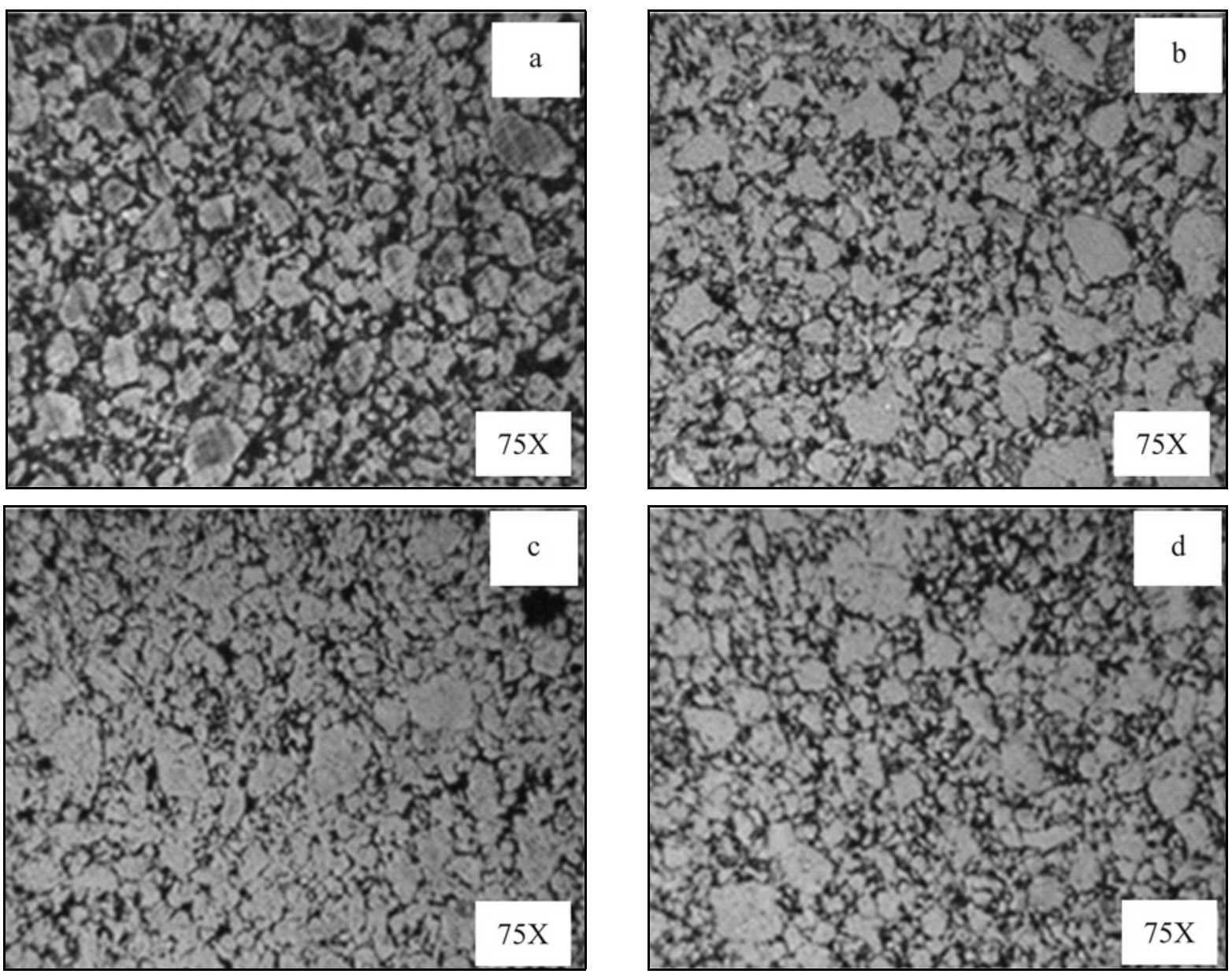

Fig. 1. The light microscope images of samples sintered at the temperatures: (a) $800{ }^{\circ} \mathrm{C}$, (b) $900{ }^{\circ} \mathrm{C},(\mathrm{c}) 1000^{\circ} \mathrm{C}$, and $(\mathrm{d})$ $1100{ }^{\circ} \mathrm{C}$.

\section{Results and discussion}

Figures 1a-d show the microscope images of samples sintered at various temperatures. Regardless of the composition and temperature synthesis, samples have similar microstructure. Following the increase of sintering temperature from 650 to $850^{\circ} \mathrm{C}$, smoother and spaceless transition was observed between the matrix and $\mathrm{M}_{7} \mathrm{C}_{3}$ carbides. At $1000^{\circ} \mathrm{C}$ where the temperature increased further, it was observed that matrix phase caused the growth of the grains, and the hardness values decreased. When mechanical milling was performed, samples were exposed to high-energy ball impacts, and powder particles placed between the ball and substrate became cold-welded to the substrate surface. As a conclusion to the mechanical process, the reaction between $\mathrm{Ni}$ and $\mathrm{Al}$ was resulting in $\mathrm{NiAl}$ compounds being formed [10]. Figure 2 shows the typical SEM micrographs of the S1.2 sample and Figs. 3a,b demonstrate EDS analysis results of the S1.2 sample. It was revealed that the more the milling time, the more the ball collisions and hence some amounts of powders were not only cold-welded but also mechani-

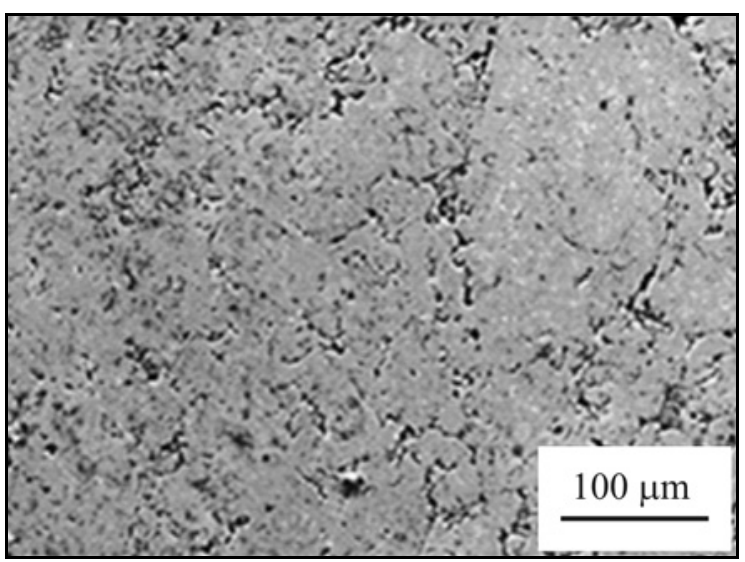

Fig. 2. SEM micrograph of the S1.2 sample.

cally triggered inter-diffusion among the particles.

The preliminary stage of mechanical alloying as indicated by the SEM micrographs had a broad range of sizes of particles. Upon having several ball collisions, the $\mathrm{Ni}$ particles diffused into the pores of $\mathrm{Al}$ pow- 

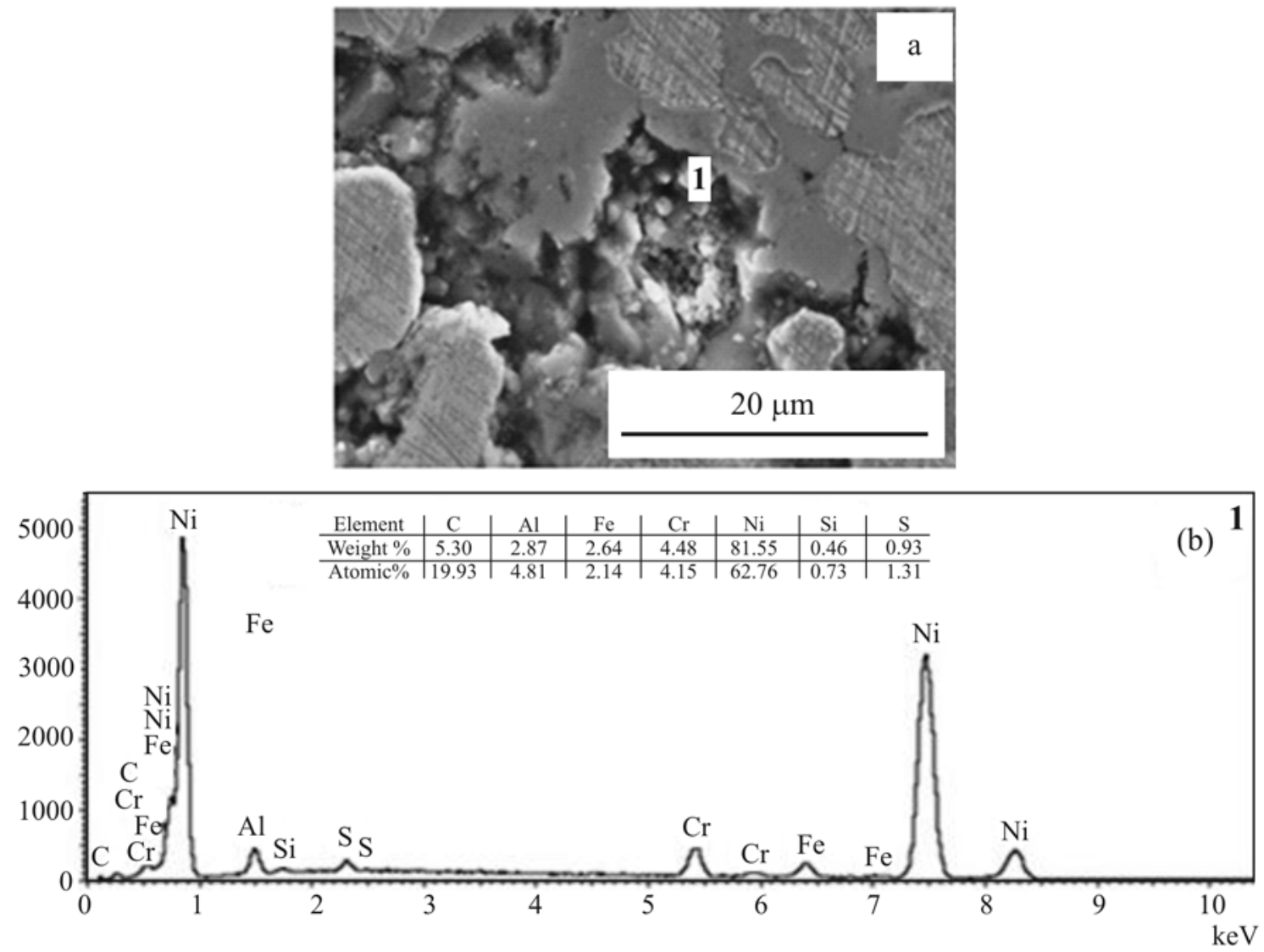

Fig. 3. EDS analysis results of the S1.2 sample.
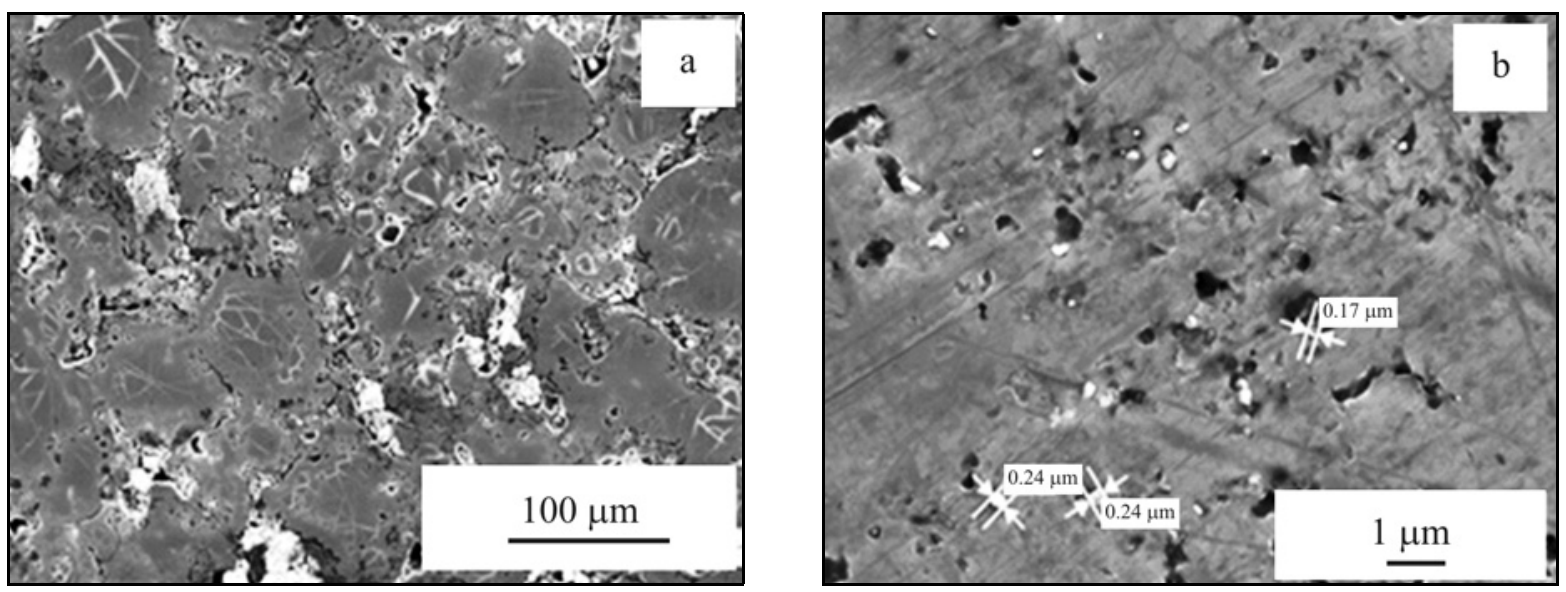

Fig. 4. SEM micrographs of the S4.3 sample.

der thus forming a thick coating. Initially, the coldwelding occurred in a non-uniform way across the sample and hence resulted in a like structure. However, increased ball milling resulted in plastic distortion while at the same time the particles were amalgamating into a material that was bulky.

Figure 4 shows the SEM micrographs of the S4.3 sample and Figs. 5a,b show EDS analysis results. Fully dense compacts in the samples were provided in the case when the sintering temperature was $850{ }^{\circ} \mathrm{C}$ for 15 min. The addition of $\mathrm{M}_{7} \mathrm{C}_{3}$ becomes clear in this ratio. After sintering, the temperature reached a higher value than the melting temperature of all intermetallic in $\mathrm{Ni}-\mathrm{Al}$ system. This results in the formation of the liquid phase and the concentration of the liquid phase throughout the sinter. The time required for the completion of concentration depends on the volumetric ratio of the liquid phase. This period increases 

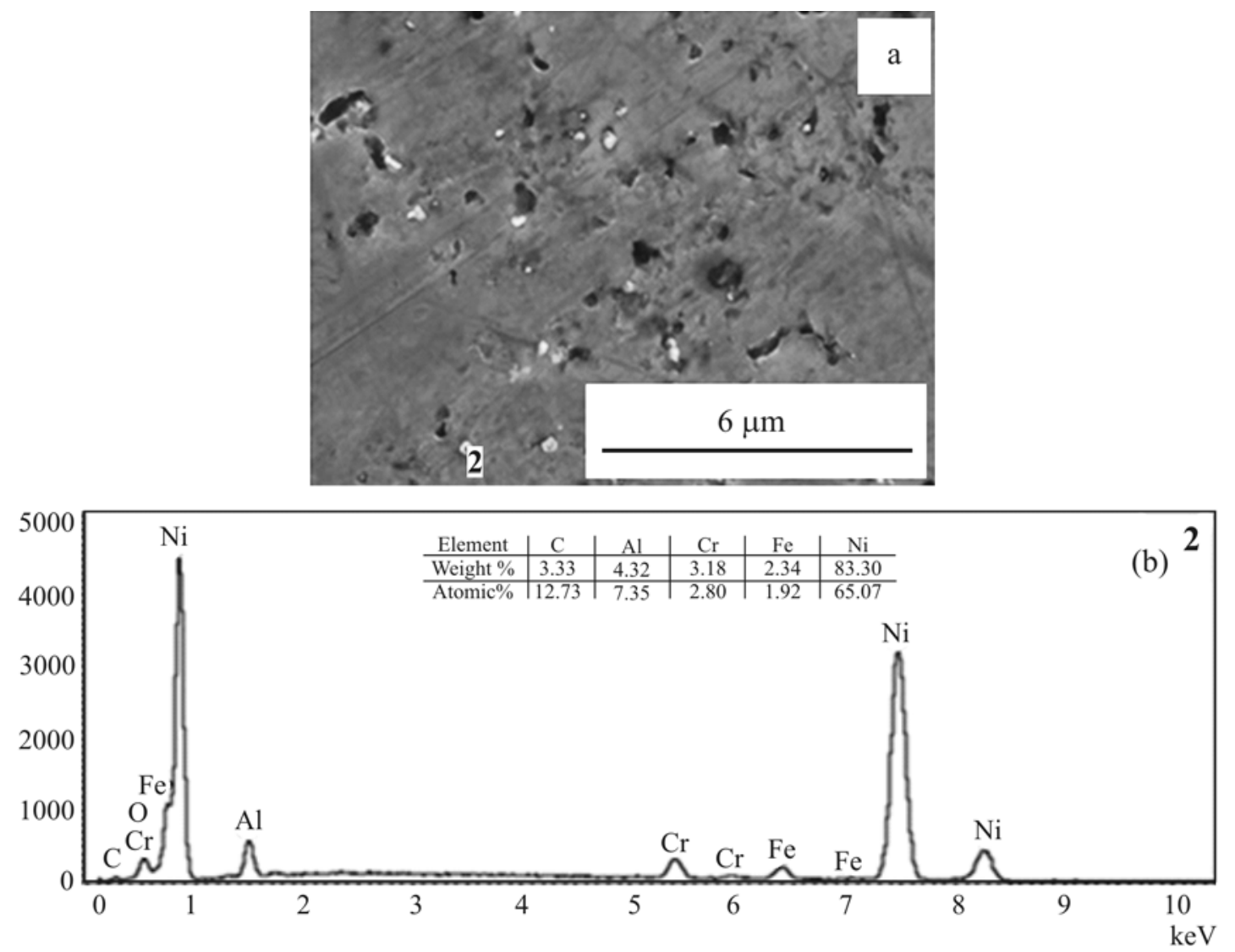

Fig. 5. EDS analysis results of the S4.3 sample.

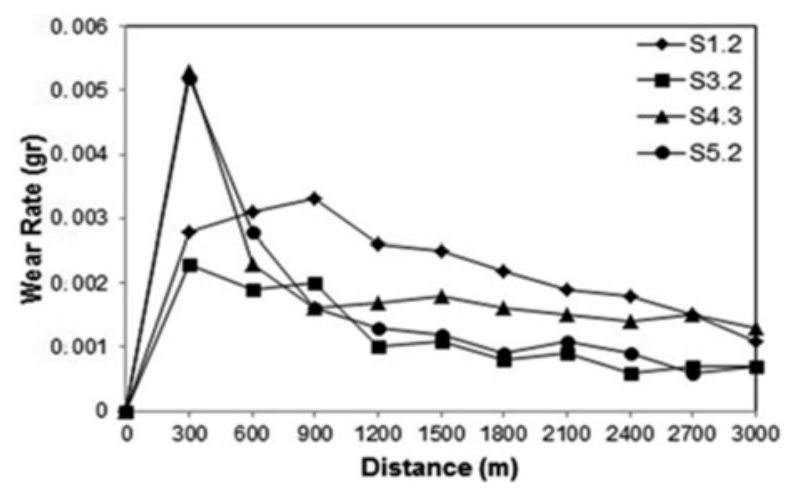

Fig. 6. Wear graphic of the samples by the sintering temperature change.

with the decrease in the volumetric ratio of the liquid phase.

The samples were subjected to wear tests based on the experimental parameters in order to identify their wear behavior. Figure 6 illustrates the wear rates of the samples in relation to the sintering temperature change. Samples of S4.3 and S5.2 were noted to have a higher wear rate at $300 \mathrm{~m}$ distance. Figure 7 illustrates the samples' wear graphic in relation to the sintering period change. Based on the correlation between the

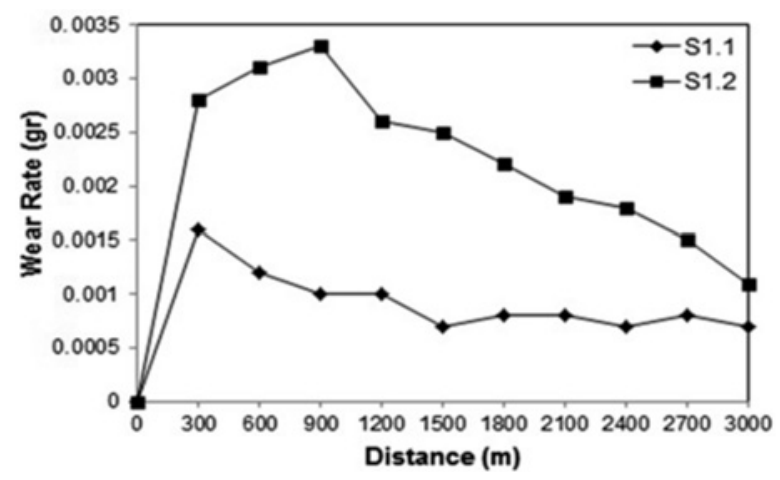

Fig. 7. Wear graphic of the samples by the sintering period change.

samples' wear graphic and sintering period change, it is evident that the wear rate of the sample $\mathrm{S} 1.2$ is greater at all distance points. Figure 8 illustrates the samples' wear graphic in relation to the change of reinforcement amount. Based on the correlation between the samples' wear graphic and the change of reinforcement amount, it is evident that although the samples S2.2, S2.3 and S2.4 had an almost similar wear rate in all distances, samples S2.1 and S2.5 had greater wear rate values particularly at 300, 600 and $900 \mathrm{~m}$. 


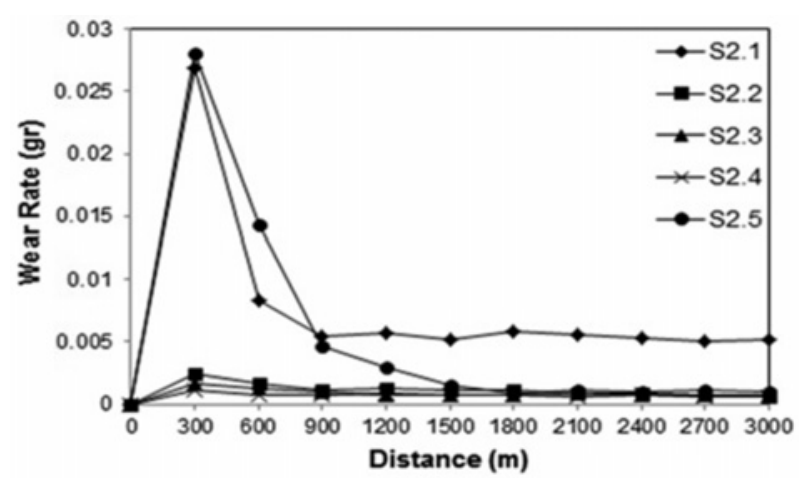

Fig. 8. Wear graphic of the samples by the change of reinforcement amount.

In addition, the $\mathrm{S} 2.1$ sample was also noted to have a high wear rate value at the $900 \mathrm{~m}$ distance point. Figure 9 illustrates the samples' wear graphic in relation to the applied load change. Based on the correlation

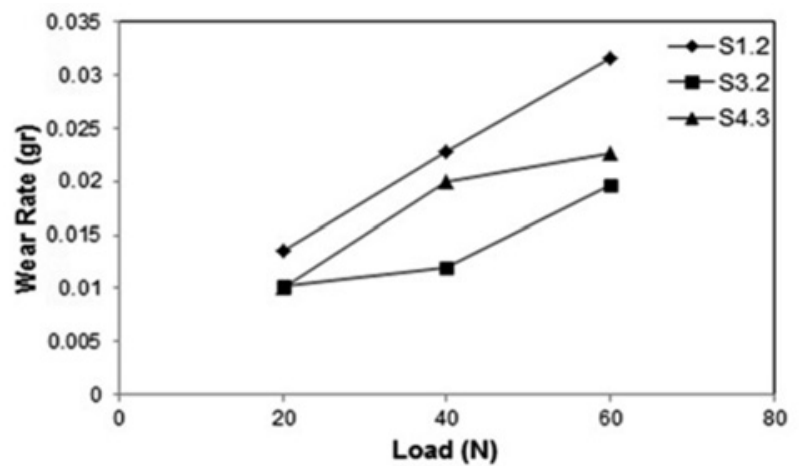

Fig. 9. Wear graphic of the samples by the applied load change.

between the samples' wear graphic and the applied load change, it is evident that although the sample $\mathrm{S} 1.2$ formed a straight line whereas sample S3.2 was more than normal under the load of $40 \mathrm{~N}$.
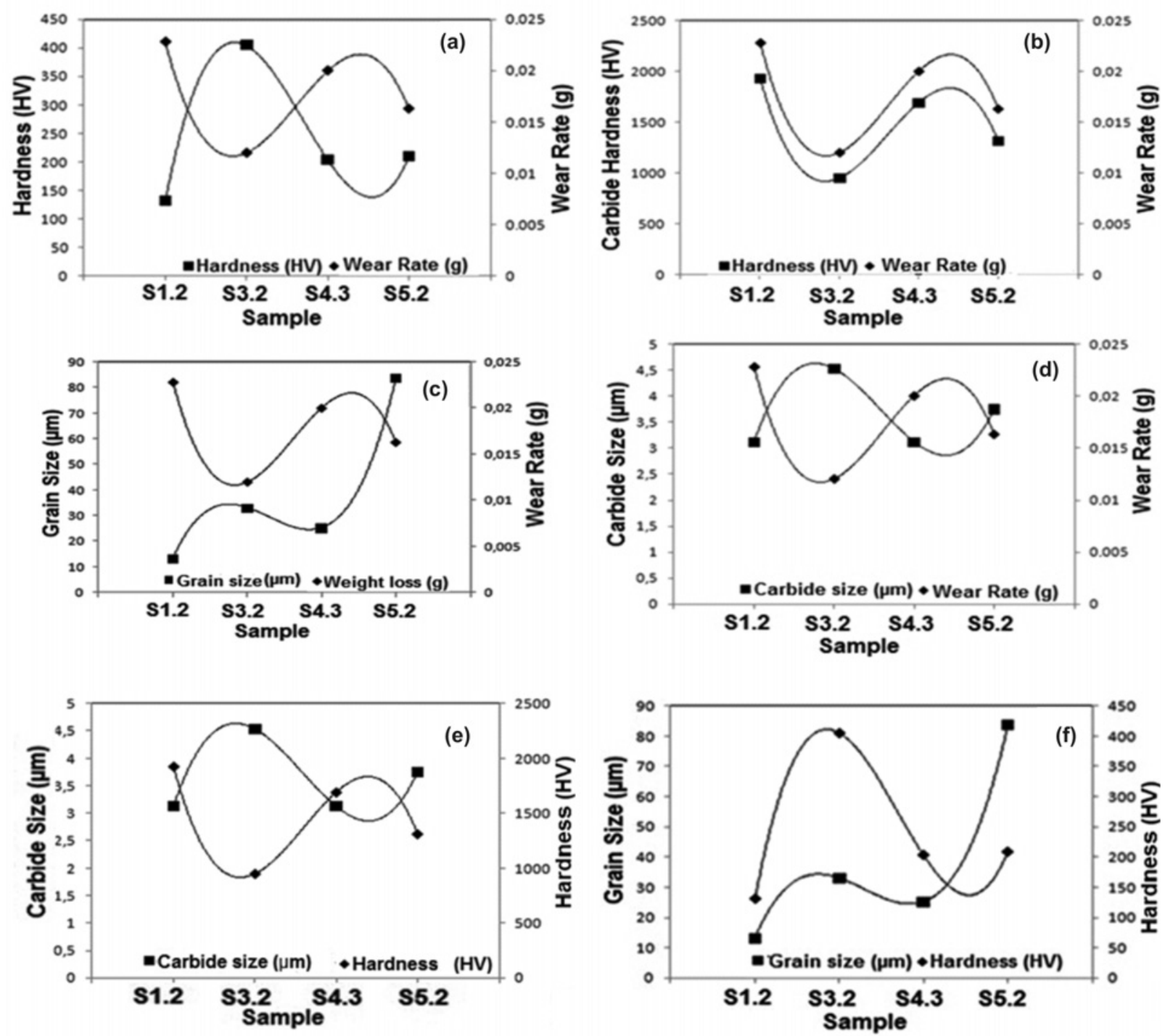

Fig. 10. The relationships between characteristic properties of the samples: (a) wear rate-hardness, (b) wear rate-carbide hardness, (c) wear rate-grain size, (d) wear rate-carbide size, (e) carbide size-hardness, and (f) grain size-hardness. 

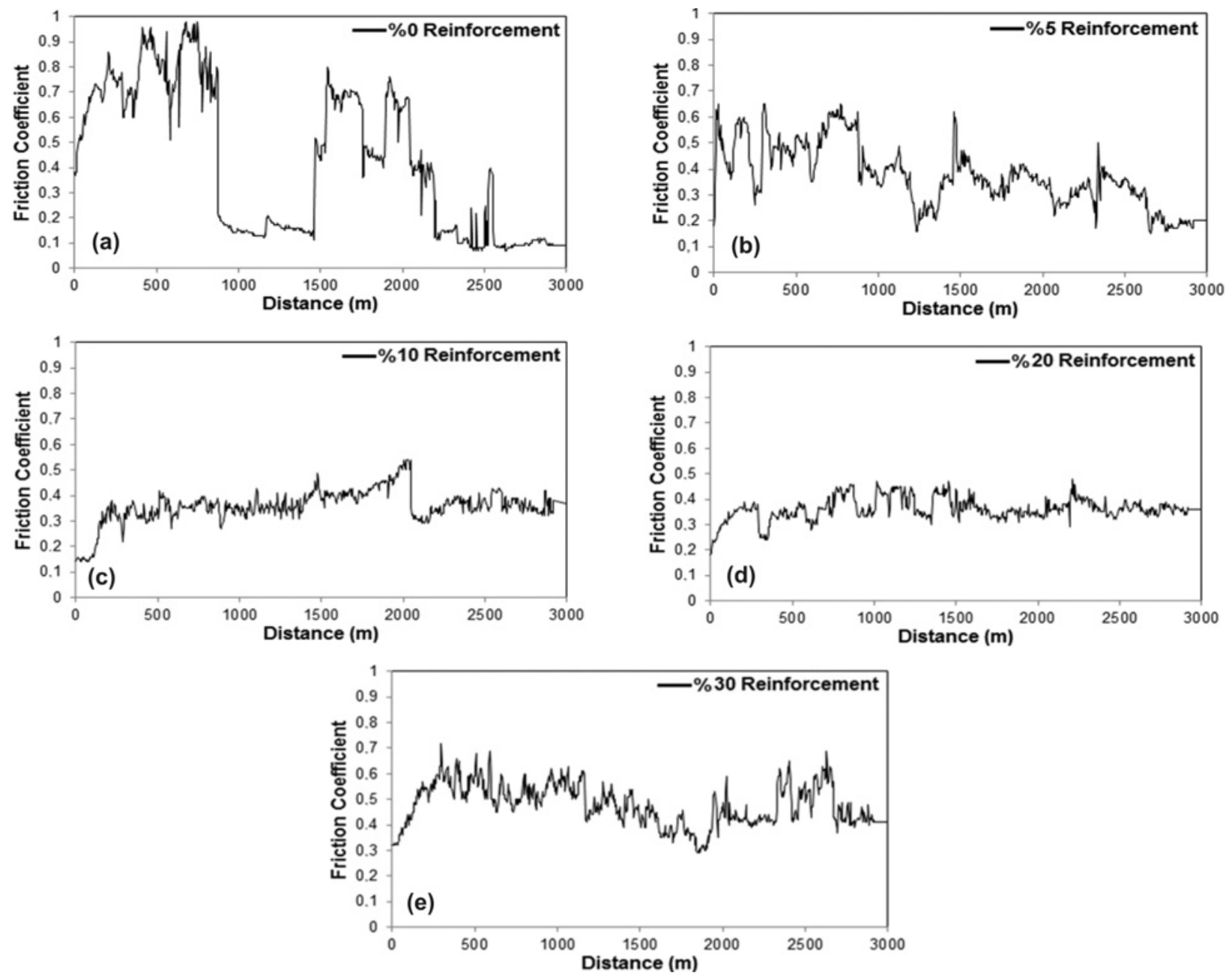

Fig. 11. The friction coefficient graphics of the samples by the change of reinforcement amount: (a) S2.1, (b) S2.2, (c) $\mathrm{S} 2.3$, (d) S2.4, and (e) S2.5 samples.

In reference to observations made when the wear rates were under sintering temperature change the lowest wear rate was recorded at $900^{\circ} \mathrm{C}$ whereas the highest wear rate was at $800^{\circ} \mathrm{C}$. Subsequently, increase in sintering period in the samples produced at $800^{\circ} \mathrm{C}$ as well as $900^{\circ} \mathrm{C}$ led to heightened wear rate. In reference to the change in reinforcement amount of the samples, it was recorded that reinforcement amount was 5,10 and $20 \%$ given weight. It is implicit to note that the wear rate was lower than wear rate amount of unreinforced samples. Nonetheless, the diminished wear rate amounts were not witnessed in the amount of $30 \%$ reinforcement. The impact of grinding time on wear rate revealed that the wear rate amount in $1 \mathrm{~h}$ of grinding was on the minimum side while the maximum wear rate amount was recorded after $2 \mathrm{~h}$ of grinding.

The relationships between characteristic properties of the samples are given in Fig. 10. When the hardness and wear rate values, the grain size and wear rate values, the carbide size and wear rate values, the carbide size and hardness values of the samples, were com- pared, there was an inverse proportion between these two characteristic properties. However, when carbide hardness and wear rate values and grain size and hardness values were contrasted, there was a direct proportion between these two characteristic properties.

Figures $11 \mathrm{a}-\mathrm{d}$ are representations of the variation of friction coefficient by reinforcement amount. The lowest friction coefficient values were observed in samples that exceeded reinforcement amount by 5, 10 as well as $20 \%$. Additionally, diminished friction coefficient was observed to the $20 \%$ reinforcement content contingent on reinforcement rate. The friction coefficient went up when the reinforcement rate rose above the aforementioned value. To this end, the continuity in friction coefficient diminished, and variation decreased contingent on reinforcement rate. The condition seemed to be a direct relation to the real abrasion rate.

The wear photos of the samples by the temperature change are given in Fig. 12. Adding FeCrC forms carbide in the matrix. Although the carbide has got a high hardness, it is also comparatively brittle. There- 

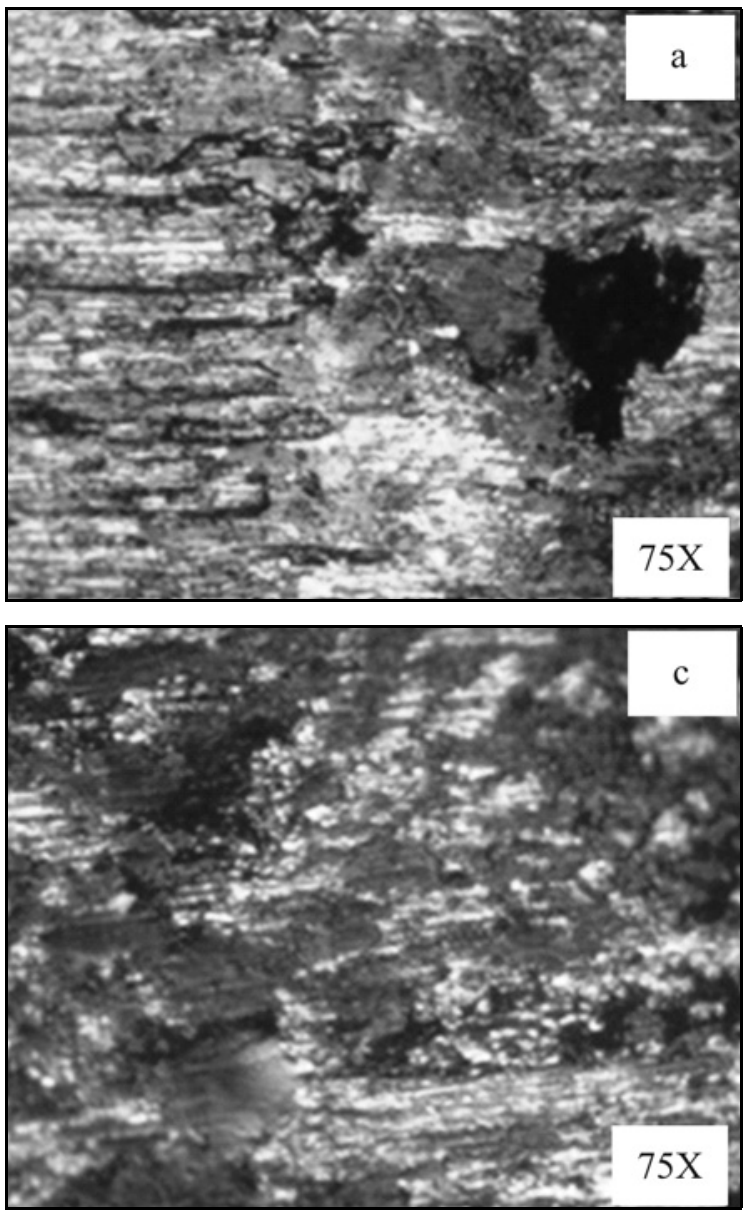
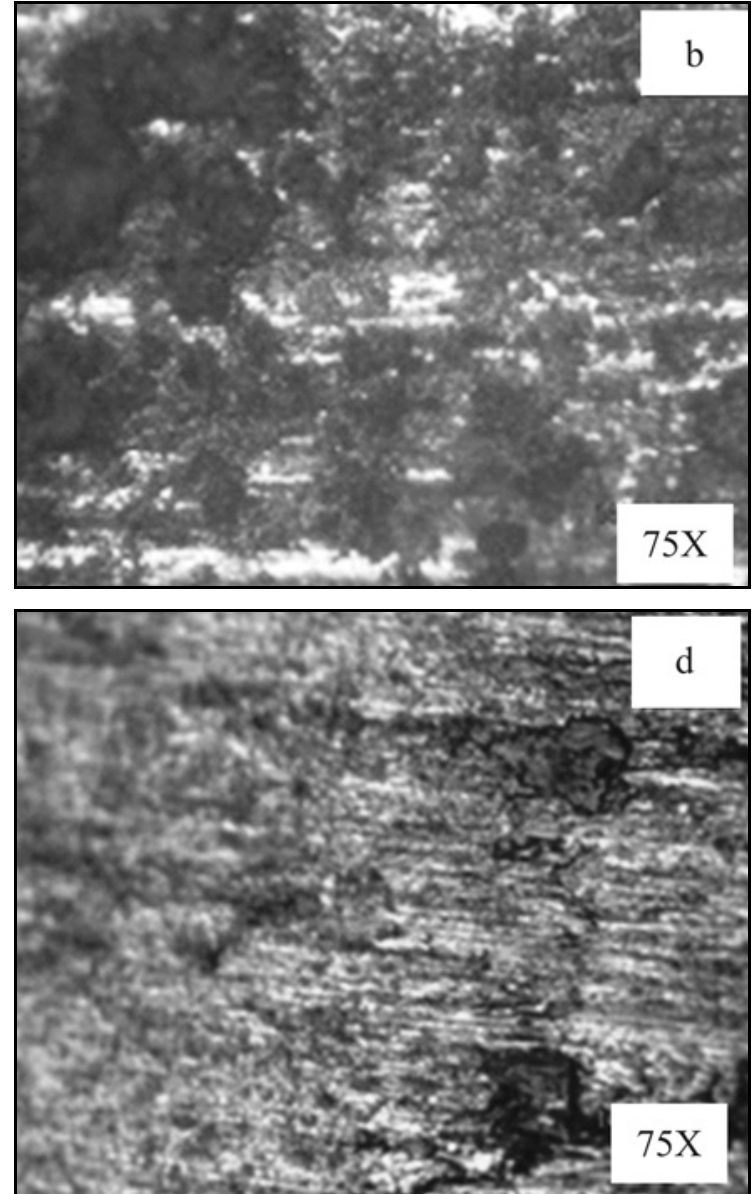

Fig. 12. The light microscope images of samples worn at temperature: (a) $800^{\circ} \mathrm{C}$, (b) $900{ }^{\circ} \mathrm{C},(\mathrm{c}) 1000^{\circ} \mathrm{C},{ }^{\circ}$ (d) $1100^{\circ} \mathrm{C}$.

fore, throughout the abrasion treatment, the carbide decomposes into a small part. The worn surfaces, after tests performed at $40 \mathrm{~N}$, were characterized by the presence of fine grooves parallel to the sliding direction and flake-like fragments, typical of delamination wear, were obtained in the wear debris. It was seen that porosity and pore shape played a determining role. Sharp-edged pores can lead to significant stress concentration effects that favor the nucleation and propagation of microcracks, leading to the easier formation of wear fragments. A decrease in porosity acquired by rising the sintering temperature and, even more, the compacting pressure led to a considerable development of the resistance to sliding wear. The materials with lower porosity contents indicated higher values of the coefficient of friction.

DTA analysis was obtained from two separate powder samples which contained reinforcement element in 0 and $10 \%$ ratio. They were milled in the spex type milling device 1 hour for mechanical alloying. These data are given in Fig. 13. The DTA analyses showed that an endothermic reaction was seen in reinforced and non-reinforced samples at around $740{ }^{\circ} \mathrm{C}$ and $780^{\circ} \mathrm{C}$, respectively. This response is predicted to be a NiAl intermetallic formation reaction. Besides, it is seen upon the review of the graphics that the reinforcement member added into the sample increased the activation energy necessary for the formation of the reaction. Therefore, it is assumed that the reaction temperature is higher in the reinforced sample. While the $\mathrm{NiAl}$ formation appears in non-reinforced samples at $1350^{\circ} \mathrm{C}$, it may decrease down to $750^{\circ} \mathrm{C}$ on average depending on the reinforcement rate and sintering temperature. It was concluded that this situation might be related to the $\mathrm{Cr}$ concentration diffused into the structure. Size and phase intensity of the $\mathrm{Ni}_{3} \mathrm{Al}$ also varied depending on the $\mathrm{Cr}$ concentration within the structure. The $\mathrm{Ni}_{3} \mathrm{Al}$ phase lessened beyond determination when the sintering temperature reached $1000{ }^{\circ} \mathrm{C}$, and it was also determined that the reinforcement carbides were dissolved completely.

\section{Conclusions}

This study describes wear resistance of $\mathrm{FeCrC}$ reinforced and Ni-based composites produced by mechanical alloying technique. Based on the experimental 

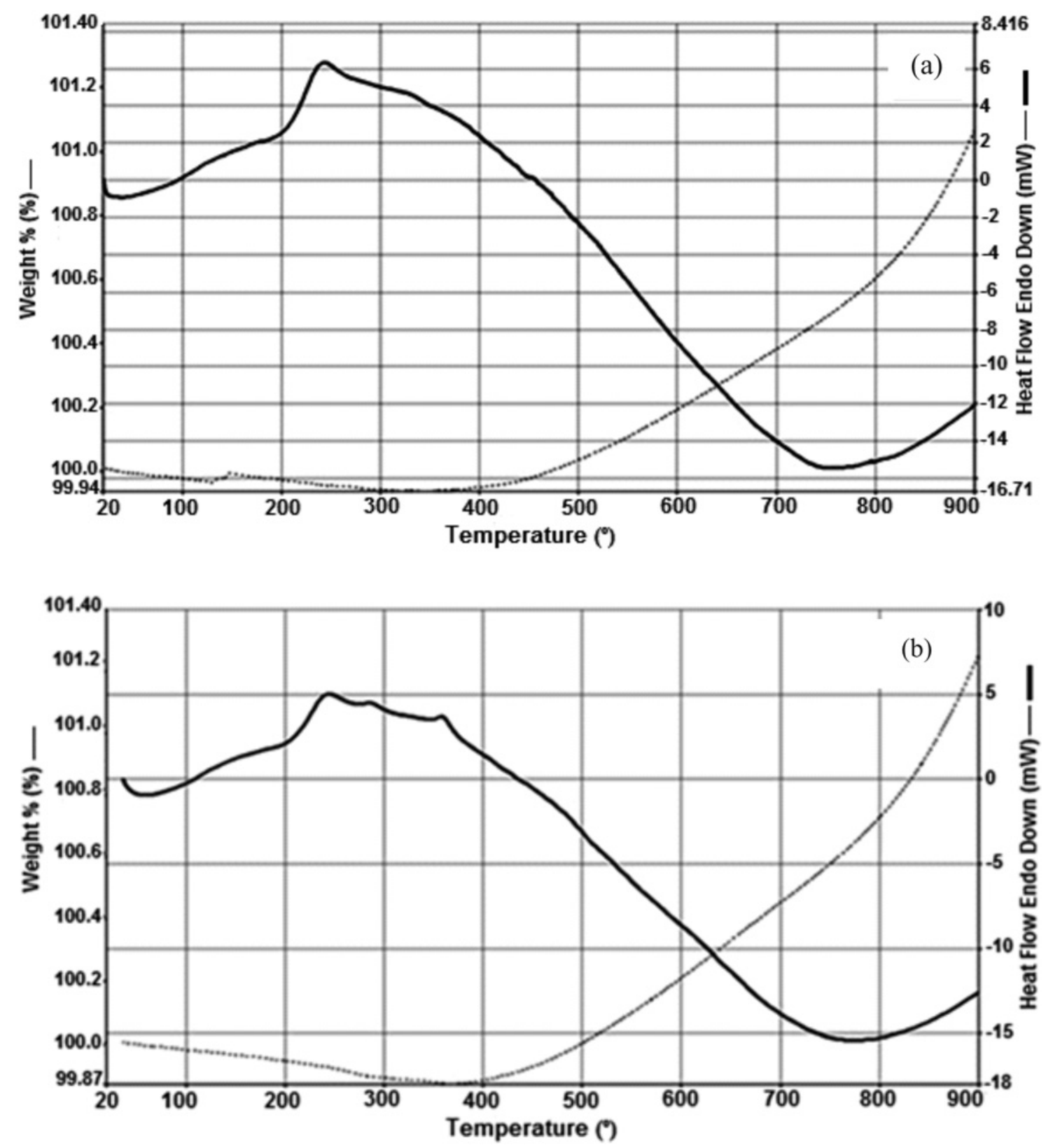

Fig. 13. DTA analyses: (a) non-reinforcement element and milled powder sample for $1 \mathrm{~h}$ and (b) $10 \%$ containing reinforcement element and milled powder sample for $1 \mathrm{~h}$.

results, the following conclusions are drawn:

1. The highest wear rate was obtained at $800^{\circ} \mathrm{C}$, and the lowest wear rate was obtained at $900^{\circ} \mathrm{C}$. In the samples produced at 800 and $900^{\circ} \mathrm{C}$, the amount of wear rate increased with the increase of sintering period. In parallel with the growth of reinforcement amount, 5, 10 and $20 \%$, the wear rate decreased. Fe$\mathrm{CrC}$ amount of powder up to $20 \%$ in the sample used as a reinforcing element brings a satisfactory conclusion.

2. The wear resistance of the reinforced samples was observed to be higher compared to the wear rate of the unreinforced specimens. However, this reduc- tion of wear rate was not observed for the amount of $30 \%$ reinforcement. It was noted that the wear rate amount for $1 \mathrm{~h}$ grinding time was minimum, the wear rate amount for $2 \mathrm{~h}$ grinding time was maximum.

3. The DTA analyses showed that an endothermic reaction was seen in reinforced and non-reinforced samples at around 740 and $780^{\circ} \mathrm{C}$, respectively. Besides, this response is predicted to be a NiAl intermetallic formation reaction. It was seen that the reinforcement added into the sample increased the activation energy necessary for the formation of the reaction. 


\section{Acknowledgement}

This work was carried out with the financial support of Namık Kemal University under project number of "NKUBAP.00.17.KR.14.01".

\section{References}

[1] Sierra, C., Vazquez, A. J.: Surface and Coatings Technology, 200, 2006, p. 4383. doi:10.1016/j.surfcoat.2005.02.176

[2] Dercz, G., Pajak, L., Formanek, B.: Journal of Materials Processing Technology, 175, 2006, p. 334. doi:10.1016/j.jmatprotec.2005.04.060

[3] Romankov, S., Kaloshkin, S. D., Hayasaka, Y., Sagdoldina, Z., Komarov, S. V., Hayashi, N., Kasai, E.: Journal of Alloys and Compounds, 483, 2009, p. 386. doi:10.1016/j.jallcom.2008.07.199

[4] Romankov, S., Sha, W., Kaloshkin, S. D., Kaevitser, K.: Surface and Coatings Technology, 201, 2006, p. 3235. doi:10.1016/j.surfcoat.2006.06.044
[5] Romankov, S., Komarov, S. V., Vdovichenko, E., Hayasaka, Y., Hayashi, N., Kasai, E.: International Journal of Refractory Metals and Hard Materials, 27, 2009, p. 492. doi:10.1016/i.ijrmhm.2008.10.005

[6] Romankov, S., Hayasaka, Y., Shchetinin, I. V., Kasai, E., Komarov, S. V., Yoon, J. M.: Materials Science and Engineering A, 528, 2011, p. 3455. doi:10.1016/j.msea.2011.01.043

[7] Suryanarayana, C.: Progress in Materials Science, 46, 2001, p. 1. doi:10.1016/S0079-6425(99)00010-9

[8] Suryanarayana, C.: Powder Metal Technologies and Applications. Volume 7. Materials Park, ASM Metals Handbook 1998.

[9] Mohammadnezhad, M., Shamanian, M., Enayat, M. H.: Applied Surface Science, 263, 2012, p. 730. doi:10.1016/i.apsusc.2012.09.151

[10] Yilmaz, S. O., Teker, T., Demir, F.: Materials Testing, 58, 2016, p. 337. doi:10.3139/120.110863 